\title{
On the identity of Lepidodexia (Orosarcophaga) ornata (Townsend, 1927) (Diptera: Sarcophagidae) and a new generic synonym
}

\author{
Cátia Antunes de Mello-Patiu ${ }^{1,2}$ \& Paula Raile Riccardi ${ }^{1,3}$ \\ 1 Universidade Federal do Rio de Janeiro (UFRJ), Museu Nacional (MN), Departamento de Entomologia. Rio de Janeiro, RJ, Brasil. \\ 2 ORCID: http://orcid.org/0000-0002-0162-0952. E-mail: camello@acd.ufrj.br \\ 3 ORCID: http://orcid.org/0000-0003-4850-7524.E-mail: paularriccardi@gmail.com
}

\begin{abstract}
The revision of the sarcophagid species Lepidodexia (Orosarcophaga) ornata (Townsend, 1927) reveals its identity and a generic synonym. The male terminalia of this species was studied in detail for the first time and revealed its congeneric affinities with Oxyvinia Dodge, 1966. Consequently, the generic status of Orosarcophaga Townsend, 1927 was revalidated, including Oxyvinia Dodge, 1966 as its junior synonym, and 0. ornata was corroborated as a valid species and name. Moreover, we provide an updated generic diagnosis of Orosarcophaga, a list of the eleven species of the genus with their distribution, and a detailed diagnosis of 0 . ornata.
\end{abstract}

Keywords. Flesh fly; Morphology; Sarcophagine; Taxonomy.

\section{INTRODUCTION}

The genus Lepidodexia sensu Pape (1996) is composed of 32 subgenera, of which 11 are monotypic (e.g., Orosarcophaga), and it is recognized mainly by some features present in the male terminalia (Pape, 1996; Buenaventura \& Pape, 2018). For some Lepidodexia species, this structure was never represented in the literature, leading to some doubts about the generic placement of such taxa, as is the case of Lepidodexia (Orosarcophaga) ornata.

The species currently recognized as Lepidodexia (Orosarcophaga) ornata (Townsend, 1927) was originally described in the monotypic genus Orosarcophaga Townsend, 1927. Later, this genus was considered a junior synonym of Lepidodexia by Pape (1996), who gave a subgeneric status to Orosarcophaga, keeping only its type species. The same action was proposed by Pape (1996) for Orodexia Townsend, 1927 and Orobrachycoma Townsend, 1927, which resulted in the secondary homonym of Lepidodexia (Orosarcophaga) ornata (Townsend, 1927), Lepidodexia (Orodexia) ornata (Townsend, 1927), and Lepidodexia (Orosarcophaga) ornata (Townsend, 1927). Also, Pape (1996) did not explain his criteria for this taxonomic arrangement but stressed that no action was taken to correct the homonymy between
Orodexia and Orosarcophaga due to the need for a revision of Lepidodexia [s.l.], with the decision being made then by the first reviser.

Townsend (1927: 342) described Orosarcophaga ornata based on one male and one female specimens, showing only general coloration characteristics. Later, Townsend (1938: 47) presented a more complete description of the genus and species and designated the male specimen as a "holotype" [correctly, it should be lectotype], but the author did not provide any aspect of the terminalia or illustrations. This type specimen had never been studied since. Therefore, the male terminalia of the lectotype of $O$. ornata was studied in detail for the first time herein, along with other specimens recently collected in Brazil.

\section{MATERIAL AND METHODS}

The lectotype of Orosarcophaga ornata housed at the National Museum of Natural History (USNM), Smithsonian Institution, Washington, was examined along with two additional specimens of the Museu Nacional (MNRJ), Universidade Federal do Rio de Janeiro, Rio de Janeiro. For morphological comparisons, seven specimens of six species of Oxyvinia and two specimens of Hallina retusa (Hall, 1933) from the MNRJ were examined, as well 
as literature data on all known Oxyvinia species. We provide additional information on the examined material between brackets.

Pictures were taken with the software LAS coupled to a stereomicroscope and assembled in software Helicon Focus 6 . After the abdomen removal, the male terminalia were treated with $10 \% \mathrm{KOH}$ at $40^{\circ} \mathrm{C}$ for $25 \mathrm{~min}$, then rinsed in 1\% acetic acid and transferred to a microvial with glycerin. Drawings were made using a camara lucida coupled to a microscope, then edited using Adobe Illustrator CS software. The external morphology nomenclature follows Cumming \& Wood (2017) and, for the distiphallus elements, Mello-Patiu \& Pape (2000), except "median stylus" and "paraphallus", which are under the concepts by Giroux et al. (2010) and Whitmore et al. (2013), respectively.

\section{RESULTS}

Aftera detailed morphological study of Orosarcophaga ornata, it is clear to state that this species indeed shares diagnostic features with members of the genus Oxyvinia Dodge, 1966, as those elucidated by Dodge (1966), Lopes (1982), Pape (1996), and Buenaventura \& Pape (2018). In consequence, we revalidate Orosarcophaga as a valid generic name. Moreover, $O$. ornata does not resemble any other species currently allocated in Oxyvinia, and it is corroborated as a valid species as well.

Ten species have been recognized in Oxyvinia, but Pape (1996) included eleven species in his catalog due to the inclusion of $O$. retusa (Hall, 1933). In the work by Pape (1996), this species was cataloged twice, as both Hallina (page 234) and Oxyvinia (page 272). Lopes (1975) reviewed the species described by David Hall from Panama and furnished its redescription as Hallina retusa. Our examination of the specimens deposited at the MNRJ also showed that $H$. retusa does not really resemble the Oxyvinia species, and we did not include it in our checklist.

Below, we provide an updated generic diagnosis of Orosarcophaga, including features of the male terminalia, a list of the eleven species of the genus with their distribution, and a detailed diagnosis of O. ornata.

\section{Genus Orosarcophaga Townsend}

Orosarcophaga Townsend, 1927: 231. Type species: Orosarcophaga ornata Townsend, 1927, by original designation. New status

Oxyvinia Dodge, 1966: 692. Type species: Oxyvinia piliventris Dodge, 1966, by original designation. New synonym

Generic diagnosis: Rows of almost parallel frontal setae; parafacial plate with setulae only; four dorsocentral postsutural setae; postalar wall setose; vein $\mathrm{R}_{1}$ bare; ctenidium on mid femur; male ST 5 with cushion-like protuberances in the inner margins of the cleft (Fig. 2B; arrow) covered by setae or spines; reddish or yellowish-brown male terminalia; apically curved pregonite relative to the base in profile; phallus with a distinct hinge between basi- and distiphallus; paraphallus bent in its proximal third; well-developed vesica with proximal section (vesical arm-shaped lever sensu Buenaventura \& Pape, 2018) covering the remaining parts and distal section bifid; juxta attached to the paraphallus with a smooth surface, often with a sclerotized distal portion and a membranous proximal portion; median stylus with a basal pair of elongated processes (capitis sensu Buenaventura \& Pape, 2018); robust lateral styli with an elongated base that extends laterally towards the paraphallus wall.

\section{Distribution: Neotropical.}

Comments: No females were available; therefore, they were not included in the generic diagnosis.

\section{Included species}

angolensis (Hall) 1937: 374 (Sarcophaga). Type locality: Chile, La Araucanía, Angol. Distribution: Chile (La Araucanía, Tarapacá). Ref. Lopes (1969); Pape (1996). New combination

excisa (Lopes) 1950: 361 (Dexosarcophaga). Brazil, Rio de Janeiro, Guanabara, Grajaú. Distribution: Peru, Argentina, Brazil (Mato Grosso, Rio de Janeiro). Ref. Lopes (1969); Pape (1996); Dufek et al. (2020). New combination

grata (Lopes) 1953: 44 (Dexosarcophaga). Type locality: Ecuador, Azuay, Cuenca. Distribution: Ecuador, Peru. Ref. Lopes (1969); Pape (1996). New combination

grisea (Lopes) 1982: 290 (Oxyvinia). Type locality: Peru, Junin, San Ramon, Estancia Naranjal. Distribution: Peru. Ref. Pape (1996). New combination

ornata Townsend, 1927: 342 (Orosarcophaga). Type locality: Brazil, São Paulo, Itaquaquecetuba. Distribution: Brazil (Rio de Janeiro, São Paulo). Ref. Lopes (1969); Pape (1996); additional material. New status

panamensis (Lopes) 1988: 132 (Oxyvinia). Type locality: Panama, Chiriqui, Potrecillos. Distribution: Panama. Ref. Pape (1996). New combination

piliventris (Dodge) 1966: 692 (Oxyvinia). Type locality: Venezuela, Cerro Avila, nr [near] Caracas. Distribution: Venezuela. Ref. Lopes (1969); Pape (1996). New combination

uraricoera (Tibana \& Lopes) 1990: 669 (Oxyvinia). Type locality: Brazil, Roraima, Rio Uraricoera, Maraca I. Distribution: Brazil (Roraima). Ref. Pape (1996). New combination

vittata (Lopes) 1982: 288 (Oxyvinia). Type locality: Bolivia, El Limbo. Distribution: Bolivia. Ref. Pape (1996). New combination

wicharti (Lopes) 1953: 46 (Dexosarcophaga). Type locality: Brazil, Rio de Janeiro, Itatiaia. Distribution: Brazil (Rio de Janeiro), Colombia. Ref. Lopes (1969); Pape (1996), Buenaventura et al. (2020). New combination

xanthophora (Schiner) 1868: 313 (Sarcophaga). Type locality: Venezuela ["Süd-Amerika"]. Distribution: Ecuador, Peru, Venezuela, Brazil (Paraná). Ref. Lopes (1969); Pape (1996). New combination 


\section{Orosarcophaga ornata Townsend, 1927 New status} (Figs. 1-2)

Type material: Lectotype male (USNM) [designated by Townsend 1938: 47, destroyed]. Brazil, São Paulo, Itaquaquecetuba (Fig. 1C). The lectotype label (Fig. 1C) does not include information on the locality, which was retrieved from Lopes (1969).

Additional material: 2 ơ $^{\wedge}$ Brazil, Rio de Janeiro, Itatiaia, Parque Nacional de Itatiaia, trilha [= trail] Rui Braga,

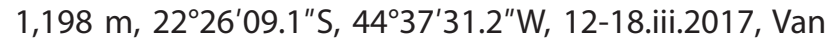
Someren - shrimp [bait], Nihei et al. leg. [MNRJ]

Diagnosis: Head and thorax with intense golden pruinosity, black abdomen with silvery-gray pruinosity; syntergosternite $7+8$ with blackish-brown anterior half and yellowish-brown posterior half; yellowish-brown epandrium, cerci, and phallus; cercal prong with acute and curved forward apex, in profile; pregonite with apical half curved and spatulate; distally dentated postgonite; juxta broad and not detached from the paraphallus, distal margin with a pair of teeth in the middle accompanied by 2-3 teeth on each side; vesica with the surface covered with microtrichiae, with two hook-like projections, in profile; broad median stylus, with one basal pair of elongated processes; long and robust lateral styli.

Male: Length: 7-9 mm $(n=3)$.

Head (Figs. 1A-B): Parafacial and fronto-orbital plates with intense golden pruinosity; parafacial plate with a row of setulae close to the eye; frons about $0.30 \mathrm{x}$ head width at ocellar triangle level; entirely blackish frontal vitta; rows of parallel frontal setae except two slightly divergent anteriormost, 9-10 well-developed frontal setae reaching pedicel apex level; reclinate orbital seta present, proclinate orbital setae absent; outer vertical setae $0.3 \mathrm{x}$ inner vertical; black ocellar triangle, ocellar setae as developed as frontals; postocular area with yellowish-gray pruinosity; gena with golden pruinosity and black setae; black postgena with slightly silvery pruinosity, black setae and some few whitish setae close to occiput; face with golden pruinosity; black facial ridge with short setulae in the inferior half; black antenna, first flagellomere with gray pruinosity and about $2 x$ longer than pedicel; arista long plumose on basal 2/3; blackish palpus.

Thorax (Figs. 1A-B): Black with intense golden pruinosity on mesonotum and scutellum, postpronotum, notopleuron, anepisternum, anepimeron, and katepisternum. Chaetotaxy: acrostichals $2-3+1$, dorsocentrals $4+4$ ( 2 longer posteriormost), intra-alars $1+2$, supra-alars $2+3$, postpronotals 3, notopleurals 4; katepisternals 3 setae almost in a straight line; setulose postalar wall; postalar callus with 2 setae; meral setae 10-11; bare proepisternum; setulose prosternum; scutellum with a pair of basal, lateral, and subapical setae (the lateral one shorter and near the subapical), a pair of preapical discal, and a pair of apical setae. Wing. Hyaline, with dark-brown veins; yellow basicosta and black tegula; bare vein $R_{1}$; vein $R_{4+5}$ with setulae dorsally on almost the entire distance to crossvein $r-m$; cell $r_{4+5}$ open at wing margin; third costal sector bare ventrally; costal spine not differentiated. Legs. Blackish-brown with silvery-gray pruinosity, yellowish-brown pulvilli; mid femur with a row of 3 median anterior setae, a row of anteroventral setae, 2 preapical posterior setae, a row of posteroventral setae with an apical ctenidium of 8-9 modified setae; mid tibia with 1 median anterodorsal, 1 apical dorsal setae, 2 basal, 1 median, and 1 apical posterodorsal setae; hind femur with a row of anterodorsal setae, a median row of anterior setae, a row of

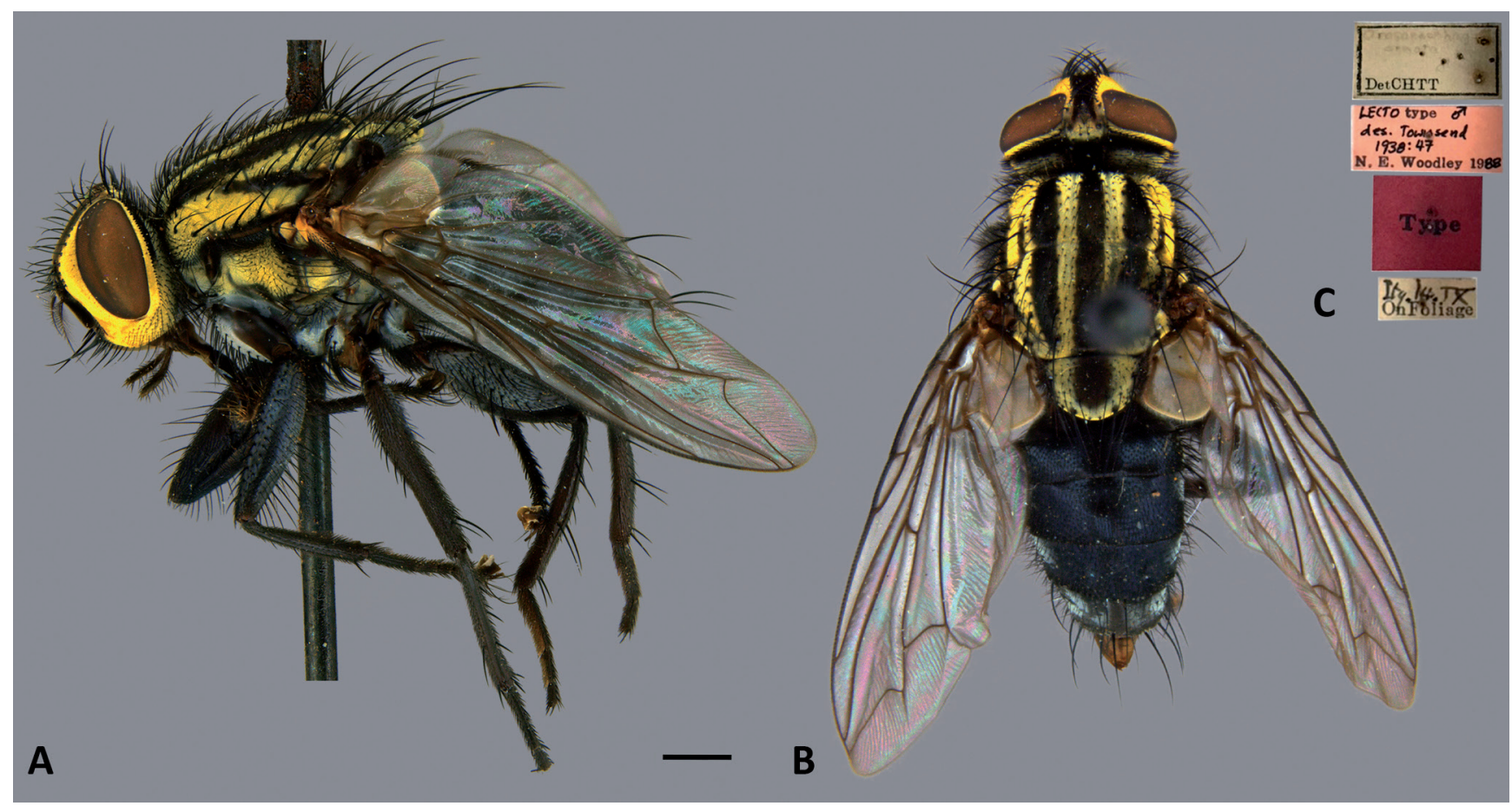

Figure 1. Orosarcophaga ornata lectotype. (A) Habitus (Scale bar: $1 \mathrm{~cm}$ ). (B) Dorsal view. (C) Label. 


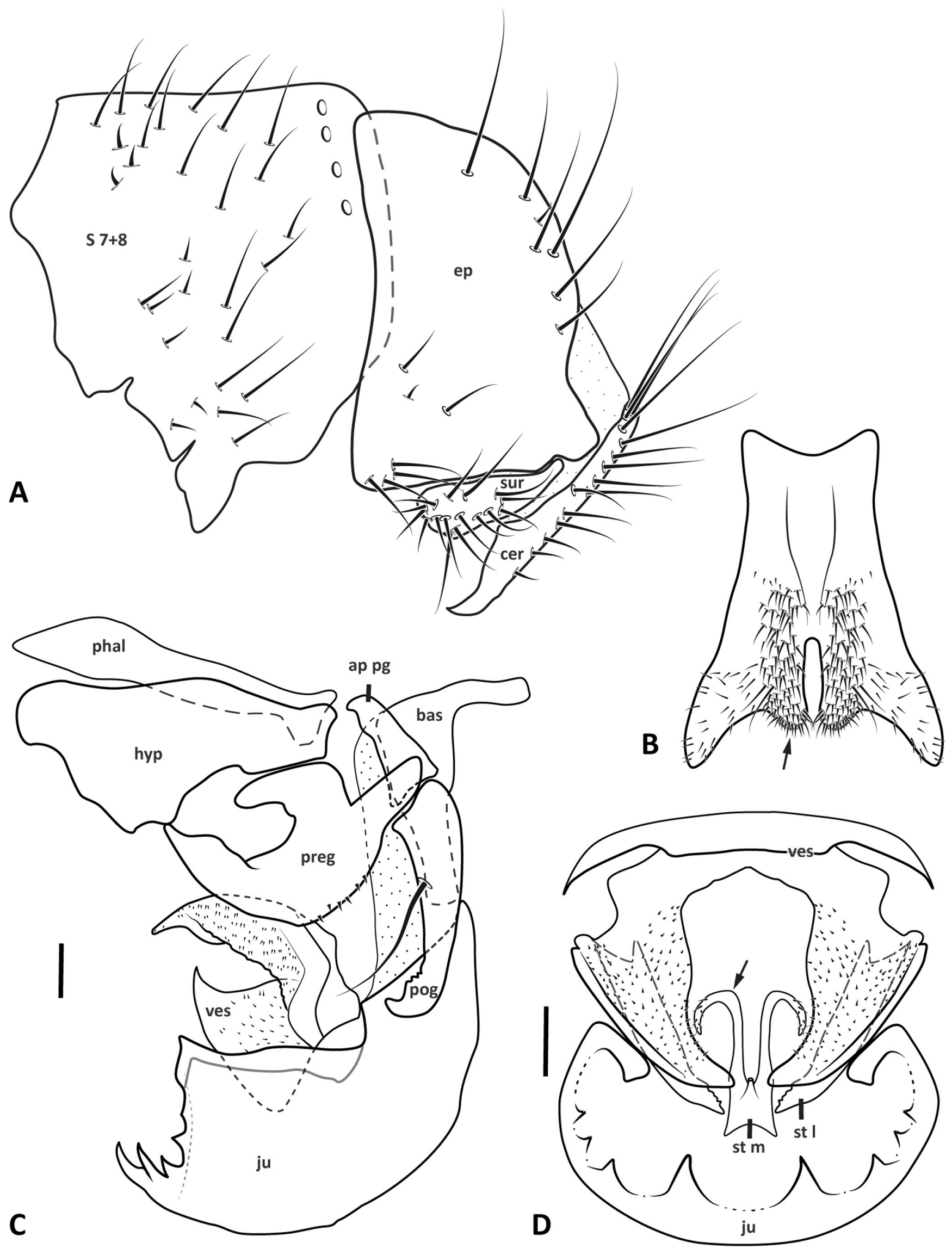

Figure 2. Orosarcophaga ornata postabdomen. (A) Male postabdomen in profile. (B) Fifth sternite; arrow indicates a cushion-like protuberance. (C) Phallic complex in profile (lectotype). (D) Phallus in ventral view (lectotype); arrow indicates an elongated process on the medial stylus. Scale bar: $1 \mathrm{~mm}$. Abbreviations: ap pg, postgonal apodeme; bas, basiphallus; cer, cercus; ep, epandrium; hyp, hypandrium; ju, juxta; phal, phalapodeme; pog, postgonite; preg, pregonite; $\$ 7+8$, syntegosternite $7+8$; st I, lateral stylus; st m, medial stylus; sur, surstylus; ves, vesica. 
anteroventral setae, 1 preapical dorsal, and 1 preapical posterior setae; hind tibia with 1 basal, 1 median, and 1 apical setae in the same position on the anterodorsal and posterodorsal margins, and 1 median anterior seta; hind coxa and trochanter with normal setae.

Abdomen (Figs. 1A-B, 2B): Black with silvery-gray pruinosity; T3 with 1 lateral marginal and no median marginal setae; T4 with 3 lateral marginal and 1 median marginal setae; T5 with a complete row of marginals (ca. 20); rectangular ST2-4, ST2-3 with numerous long hair-like pale setae and some black ones; ST3-4 with a patch of black setae on the middle of the posterior margin; blackish ST5 with a cushion-like elongated process in the inner margins, covered by spinous setae (Fig. 2B).

Terminalia (Figs. 2A, 2C-D): Syntergosternite $7+8$ with blackish-brown anterior half and yellowish-brown posterior half, 4-5 pairs of well-developed marginal setae; yellowish-brown epandrium, cerci, and phallus; epandrium with sparse setae, longer on the dorsal surface (Fig. 2A); clavate surstylus with long setae on the apical half (Fig. 2A); broad cercal prongs, parallel but separated, in posterior view, with acute, blackish, and curved forward apex, in profile (Fig. 2A); long pregonite, apical half curved and spatulate, and postgonite as long as the pregonite, with a long median setae and distally dentate (Fig. 2C); separated basi- and distiphallus, short basiphallus, about $0.5 \mathrm{x}$ the paraphallus length (Fig. $2 \mathrm{C}$ ); broad juxta not detached from the paraphallus, distal margin with a pair of teeth in the middle accompanied by 2-3 teeth on each side (Figs. 2C-D); pilose vesica with two hook-like projections, in profile, which are an odd upper lobe covering a bifid lower lobe, in ventral view (Figs. 2C-D); broad median stylus with one basal pair of elongated processes (Fig. 2D; arrow); long and robust lateral styli (Fig. 2D).

Remarks: The lectotype was on loan at the MNRJ and, unfortunately, it was lost during the fire which destroyed the MNRJ Entomological Collection (Duarte, 2019). We observed that there are individual differences in the number of teeth in the juxtal lateral dentation among the specimens examined ( 2 or 3 teeth on each side of the median teeth pair).

\section{DISCUSSION}

Despite the presence of setae on the postalar wall, Orosarcophaga ornata does not possess the vesica C-shaped with a convex distal section, juxta angled relative to the phallic tube, developed bacilliform sclerite, nor a spinose lobe above the vesica, all diagnostic characteristics of the genus Lepidodexia (Pape, 1996; Buenaventura \& Pape, 2018; Riccardi \& Mello-Patiu, 2020). Also, the result of an ongoing morphological phylogeny of Lepidodexia shows O. ornata nested with O. xanthophora, separated from all the remaining species of Lepidodexia (Riccardi \& Mello-Patiu, 2020). In the phylogenetic hypothesis of Sarcophaginae proposed by Buenaventura \& Pape (2018), three species of the former Oxyvinia were nested with Dexosarcophaga species; however, Orosarcophaga ornata was not included in the taxonomic sample. Riccardi \& Mello-Patiu (2020) nested Orosarcophaga with Oxysarcodexia Townsend instead of Dexosarcophaga Townsend, but the taxon sampling of Sarcophaginae except Lepidodexia was limited. Despite the differences aforementioned, both phylogenies indicate that Orosarcophaga (including Oxyvinia) does not belong to Lepidodexia.

The male terminalia elements of sarcophagids are often the most reliable morphological features to establish phylogenetic relationships (Giroux et al., 2010; Buenaventura \& Pape, 2018). In this sense, the most conspicuous characteristic gathering the members of the former Oxyvinia into Orosarcophaga is the median stylus with a peculiar basal pair of elongated processes, which seems to be a unique feature within Sarcophaginae (Fig. 2D; arrow). Additionally, the type species of Orosarcophaga also share with $O$. vittata and O. xanthophora the presence of a dentate margin on the apex of juxta. This evidence, along with the remaining features discussed above, supports our taxonomic decision.

\section{ACKNOWLEDGMENTS}

We thank Norman E. Woodley (USNM) for the loan of the lectotype. C.A.M.P. is grateful to FAPERJ for its financial support (Proc. E-26/200.078/2019) and CNPq for the Research fellowship (308951/2018-2). P.R.R. is supported by a postdoctoral fellowship from the CAPES/CNPQ Acordo Program - PROTAX II - Project 440482/2015-1 (Proc. 176040/2018-00 and 333912/2019-00).

\section{AUTHORS' CONTRIBUTIONS}

C.A.M.P.: contribution statement - this author was the major contributor of the manuscript, provided the background history of Orosarcophaga, the updated generic diagnosis, the list of species, and analyzed the remaining species of the genus. P.R.R.: contribution statement - this author provided insights into all sections of the manuscript, the images and illustrations, participated actively in the material and methods section, the written characterization of Orosarcophaga ornata, and the discussion.

\section{REFERENCES}

Buenaventura, E. \& Pape, T. 2018. Phylogeny, evolution and male terminalia functionality of Sarcophaginae (Diptera: Sarcophagidae). Zoological Journal of the Linnean Society, 183(4): 808-906.

Buenaventura, E.; Valverde-Castro, C. \& Wolff, M. 2020. New carrion-visiting flesh flies (Diptera: Sarcophagidae) from tropical dry forests of Colombia and their phylogenetic affinities. Acta Tropica, 213(2021): 1-14. DOI

Cumming, J.M. \& Wood, D.M. 2017. Adult morphology and terminology. In: Kirk-Spriggs, A.H. \& Sinclair, B.J. (Eds.). Manual of Afrotropical Diptera. 
Volume 1. Suricata 4. Pretoria, South African National Biodiversity Institute., Chapter 3, p. 89-133.

Dodge, H.R. 1966. Some new or little-known Neotropical Sarcophagidae (Diptera), with a review of the genus Oxysarcodexia. Annals of the Entomological Society of America, 59(4): 674-701.

Duarte, L.F.D. 2019. 0 Museu Nacional: ciência e educação numa história institucional brasileira. Horizontes Antropológicos, 25(53): 359-384.

Dufek, M.I.; Mello-Patiu, C.A.\& Mulieri, P.R. 2020. Inventory of Sarcophaginae (Diptera: Sarcophagidae) for the Humid Chaco, a poorly surveyed ecoregion of South America. Journal of Natural History, 54(5-6): 367-403.

Giroux, M.; Pape, T. \& Wheeler, T.A. 2010. Towards a phylogeny of the flesh flies (Diptera: Sarcophagidae): morphology and phylogenetic implications of the acrophallus in the subfamily Sarcophaginae. Zoological Journal of the Linnean Society, 158(4): 740-778.

Lopes, H.S. 1969. Family Sarcophagidae. A catalogue of the Diptera of the Americas south of the United States. São Paulo, Departamento de Zoologia, Secretaria da Agricultura. n. 103, 88p.

Lopes, H.S. 1975. On some Sarcophagidae described by David G. Hall from Panama, with description of a new genus (Diptera). Revista Brasileira de Biologia, 34(2): 231-236.
Lopes, H.S. 1982. Notes on American Sarcophagidae (Diptera) with descriptions of seven new species. Revista Brasileira de Biologia, 42(2): 285-294.

Mello-Patiu, C.A. \& Pape, T. 2000. Definitions of Dexosarcaphaga Townsend 1917 and Sarcofahrtiopsis Hall 1933, including two new species a redescription of Sarcofahrtiopsis cuneata (Townsend 1935) (Diptera: Sarcophagidae). Boletín de Entomología Venezolana, 15(2): 181-194.

Pape, T. 1996. Catalogue of the Sarcophagidae of the world (Insecta: Diptera). Associated Publishers. 557p. (Memoirs on Entomology, International, 8).

Riccardi, P.R. \& Mello-Patiu, C.A. 2020. Filogenia de Lepidodexia Brauer \& Bergenstamm (Diptera: Sarcophagidae). In: Congresso Brasileiro de Zoologia, 33․ [poster presentation].

Townsend, C.H.T. 1927. Synopse dos genero muscoideos da região humida neotropical da America, com generos e especies novas. Revista do Museu Paulista, 15: 203-385 + 4 pls + 4p. errata.

Townsend, C.H.T. 1938. Manual of myiology. Part VI. Muscoid generic diagnoses and data. Stephanostomatini to Moriniini. Itaquaquecetuba, São Paulo. 309p.

Whitmore, D.; Pape, T. \& Cerretti, P. 2013. Phylogeny of Heteronychia: the largest lineage of Sarcophaga (Diptera: Sarcophagidae). Zoological Journal of the Linnean Society, 169(3): 604-639. 